\title{
FACTORS INFLUENCING THE USAGE OF MOBILE SHOPPING APPLICATIONS AND THE IMPACT OF THESE FACTORS ON SATISFACTION AND INTENTION TO USE
}

\author{
DOI: 10.17261/Pressacademia.2018.904 \\ PAP- V.7-2018(57)-p.306-310
}

Tevfik Sukru Yaprakli ${ }^{1}$, Zeynep Kacer ${ }^{2}$, Musa Unalan ${ }^{3}$

${ }^{1}$ Ataturk University, Department of Business Administration, Erzurum, Turkey.

sukruyaprakli@atauni.edu.tr, ORCID: 0000-0002-1756-1491

${ }^{2}$ Ataturk University, Department of Marketing, Erzurum, Turkey.

zeynep.kacer1@gmail.com, ORCID: 0000-0003-3956-0999

${ }^{3}$ Firat University, Department of Business Administration, Elazig, Turkey.

munalan@firat.edu.tr, ORCID: 0000-0002-1900-0815

To cite this document

Yaprakli, T. S., Kacer, Z., Unalan, M. (2018). Factors influencing the usage of mobile shopping applications and the impact of these factors on satisfaction and intention to use. PressAcademia Procedia (PAP), V.7, p.306-310.

Permemant link to this document: http://doi.org/10.17261/Pressacademia.2018.904

Copyright: Published by PressAcademia and limited licenced re-use rights only.

\section{ABSTRACT}

Purpose- The purpose of this study is to determine the impact of perceived risk, perceived enjoyment, perceived usefulness, perceived ease of use on satisfaction and intention to use in mobile shopping applications.

Methodology- For testing the proposed hypotheses, a survey instrument is designed to measure different constructs. Convenience sampling method was used in this study. Data collected from Erzurum in Turkey. After the validation and cleaning of data by removal missing entries, a total of 389 respondet data points is available for carrying out further analysis.

Findings- The multiple regression results show that satisfaction and intention to use are influenced by perceived usefulness, perceived ease of use and perceived enjoyment. Also, perceived risk have a significant effect on satisfaction whereas the effect of perceived risk is nonsignificant on intention to use.

Conclusion- The seven of eight hypotheses are accepted in our model. The results show that participants have hihger perceived risk when they use to mobile shopping applications.

Keywords: Technology acceptance model, perceived risk, perceived enjoyment, satisfaction, mobile shopping applications. JEL Codes: M10, M30, M31

MOBIL ALIŞVERIŞ UYGULAMALARININ KULLANIMINI ETKILEYEN FAKTÖRLER VE BU FAKTÖRLERIN MEMNUNIYET VE KULLANMA NIYETi ÜZERINDEKI ETKISI

\section{ÖZET}

Amaç- Araştırmanın amacı, tüketicilerin mobil alışveriş uygulamaları kullanımında algıladıkları risk, kullanışlıık, kullanım kolaylığı ve keyifin, memnuniyet ve kullanma niyeti üzerindeki etkisini belirlemektir.

Yöntem- Veri toplama metodu olarak anket yöntemi seçilmiştir. Anket çalışması kolayda örnekleme yöntemi kullanılarak yapılmıştır. Araştırmanın ana kütlesini Erzurum il sınırlarında yaşayan 18 yaş ve üzeri katılımcılar oluşturmaktadır. 412 kişiye uygulanan anketin hatalı ve eksik cevapları elendikten sonra 389 adet anket formu değerlendirmeye tabi tutulmuştur.

Bulgular- Yapılan çoklu regresyon analizi sonucunda, algılanan kullanışlılık, algılanan kullanım kolaylığı ve algılanan keyif kullanma niyeti ve memnuniyet üzerinde etkili olduğu görülmüştür. Ayrıca algılanan riskin memnuniyet üzerinde etkisi olmasına rağmen kullanma niyeti üzerinde etkisinin olmadığı sonucuna ulaşılmıştır.

Sonuç- Araştırma için belirlenen 8 hipotezden 7'si kabul 1'i red edilmiştir. Katılımcıların mobil alışveriş uygulamalarını kullanırken algıladıkları riskin yüksek olduğu tespit edilmiştir.

Anahtar Kelimeler: Teknoloji kabul modeli, algılanan risk, algılanan keyif, memnuniyet, mobil alışveriş uygulamaları. JEL Kodları: M10, M30, M31 


\section{GíRiş}

Her geçen gün gelişen teknoloji ile birlikte tüketici istek ve ihtiyaçları da değişim göstermektedir. Artık tüketiciler geleneksel alışveriş alışkanlıkları yerine sanal ortamlarda alışveriş yapmayı tercih etmektedir. Hayatı kolaylaştıran akılı telefon, bilgisayar, tablet gibi teknolojiler ile beraber mobil internet sayesinde tüketiciler zaman ve mekan sınırı olmadan istedikleri her türlü ürün veya hizmete kolayca ulaşabilmektedir. Tüketicilere mobil araçlardan ulaşmanın avantajlarını keşfeden firmalar, ibreyi mobil ticarete doğru kaydırmaktadır. Bu çalışmada tüketicilerin mobil alışveriş uygulamalarına yönelik algıladıkları risk, kullanışlılık, kullanım kolaylığı ve keyifin kullanma niyeti ve memnuniyet üzerindeki etkisi araştırılmıştır.

\section{LITERATÜR}

\subsection{Teknoloji Kabul Modeli}

Fishbein ve Ajzen'in (1975) önerdikleri ve Türkçesi "Sebepli Davranış Teorisi" olan TRA (Theory of Reasoned Action) neredeyse tüm insan davranışlarını açıklamak için sosyal psikolojik alanında geniş bir şekilde incelenmiş niyet modelidir. TRA, sosyal davranışların, bireylerin tutumlarına bağlı olduğunu savunmaktadır (Davis ve diğ., 1989). Davis 1989 yılında teorik zemin olarak TRA'yı kullandığı Teknoloji Kabul Modelini geliştirmiştir. Teknoloji Kabul Modeli'nin amacı bilgi teknolojilerinin son kullanıcıları tarafından kabulünde etkili olan bilişsel ve duyuşsal faktörleri belirlemektir (Davis ve diğ., 1989). TKM teorisi bilgi teknolojileri kullanma davranışının iki belirleyici unsuru içerisinde bulundurur; Algılanan Kullanışlılık (AK), Algılanan Kullanım Kolaylığı (AKK) (Davis ve diğ., 1989). Literatür incelendiğinde bu iki etkenin farklı bilgi teknolojileri kullanma niyetlerini ölçmede önemli etkisi ve yaygın kullanımı çeşitli çalışmalar tarafından kanıtlanmıştır (King ve He, 2006; Lee ve diğ.,2003). Mobil alışveriş uygulamaları gibi belirli bir sistemin kullanıcılar tarafından benimsenmesinde TKM teorisini kullanmak daha uygundur. Çünkü TKM belirli teknolojilere özgü yeni değişkenler ekleyerek teoriyi kolayca genişletmek için fırsatlar sunar (Kim ve diğ., 2010).

\subsection{Algılanan Risk}

Algılanan risk kavramı pazarlama literatüründe ilk kez 1960 yılında Raymond Bauer tarafından ele alınmıştır. Bauer, tüketicilerin satın alma davranışında oluşacak sonuçların belirsizlik içerdiği ve bu sonuçlardan en azından bir kısmının istenildiği gibi olmaması bakımından risk içerdiğini ifade etmiştir (Ross, 1975). Algılanan risk karşılaşılabilecek olumsuz sonuçların belirsizliğini ölçen bir yapıdır (Gillet, 1976) ve tüketicilerin gösterdikleri satın alma davranışlarının önemli bir belirleyicisi olduğu kabul edilmektedir (Kim ve diğ., 2009). Diğer bir tanıma göre, tüketicinin bir ürün veya hizmet satın almasından kaynaklanabilecek olumsuz sonuçlara yönelik algısıdır (Dowling ve Staelin, 1994). Algılanan risk yaygın olarak "kişinin bir ürün veya hizmetlerin olası olumsuz sonuçları ile ilgili yaşadığı belirsizlik hissi” şeklinde tanımlanmaktadır (Pavlou ve Featherman, 2003). Algılanan risk, tüm satın alma davranışı tiplerinde ve tüketicilerin hangi ürünü, nereden, nasıl ve ne zaman satın alacağı gibi karar alma sürecinin her aşamasında önemli rol oynamaktadır (Mitchell, 1992). Literatürdeki birçok çalışma algılanan riskin tüketicilerin bir teknolojiyi benimsemeleri konusunda oldukça önemli rol oynadığını ortaya koymaktadır (Kim ve diğ., 2008; Wu ve Wang, 2005).

\subsection{Algılanan Kullanışlııı}

Teknoloji Kabul Modeli'nin temel değişkenlerinden birisi olan algılanan kullanışlılık bireyin belirli bir sistemi kullanarak kendi iş yapabilirlik düzeyini artıracağına olan inanma derecesidir (Davis, 1989). Diğer bir tanıma göre, bireyin yeni bir teknolojik sistem kullandığında algıladığı toplam değerdir (Kim ve diğ., 2007). Agrebi ve Jallais' e göre mobil ticaret kapsamında algılanan kullanışlılık, söz konusu sistemi kullanırken gerçekleştirilen görevlerin iyileştirilmesine ilişkin bireylerin algısıdır (2005). Algılanan kullanışlılık bireylerin teknolojiyle etkileşiminde ve mobil hizmete olan güvenin artmasında önemli rol üstlenir. (Giovannini ve diğ., 2015). Çünkü bireyler satın alma davranışlarının sonuçlarını algıladıkları kullanışlılık açısından değerlendirir ve arzu edilen beklentiler ile gösterilen performansın başarısı göz önünde bulundurularak yeniden kullanma eğilimi yansıtırlar (Venkatesh ve diğ., 2003). Algılanan kullanışlılık maliyetlerin azalması, ürünü elde etmek için gereken süreden tasarruf, etkinliğin artması, işlemler arasındaki zamanın kısalığı gibi faydalardan kaynaklanmaktadır (Shih, 2004). Algılanan kullanışlılığın teknolojinin kullanıc tarafından benimsenmesinin ve kullanma niyetinin önemli bir belirleyicisi olduğu birçok çalışmada kanıtlanmıştır (Tsu ve diğ., 2009; Davis ve diğ., 1989).

\subsection{Algılanan Kullanım Kolaylığı}

Teknoloji Kabul Modeli'ne göre algılanan kullanım kolaylığı, bir kişinin belirli bir teknolojiyi kabul etme ve kullanma niyetini belirlemede önemli rol oynamaktadır (Davis ve diğ., 1989; Kucukusta ve diğ., 2015). Algılanan kullanım kolaylığı "bir kişinin bir teknolojik uygulamayı zihinsel bir çaba harcamadan kullanma derecesidir" (Davis, 1989). Literatürde birçok çalışmada algılanan kullanım kolaylığı ve memnuniyet arasında anlamlı ilişki olduğu tespit edilmiştir (Wu ve Wang, 2005; Khalifa ve Ning Shen, 2008; Dai ve Palvi, 2009). Ancak tüketicilerin mobil alışveriş için akılı telefon kullanma niyetini araştıran Agrebi ve Jallais çalışmasında algılanan kullanım kolaylığı ve memnuniyet arasında anlamlı bir ilişki olmadığını tespit etmiştir (2015). Algılanan kullanım kolaylığının davranışsal niyet ile pozitif yönde ilişkili olduğunu kanıtlayan çalışmalar da bulunmaktadır (Gefen ve Straub, 2003; Venkatesh ve Davis, 2000).

\subsection{Algılanan Keyif}

Algılanan keyif, teknoloji kullanımında elde edilen faydanın yanı sıra kişinin faliyetlerden algıladığı keyif derecesidir (Davis ve diğ., 1992). Teknolojiyi kullanmanın ne kadar zevkli görüldüğünü açıklayan bir kavram olarak ele alınmaktadır (Nysveen ve diğ., 2005). Algılanan keyif, alışveriş için tek başına ikna etme potansiyeline sahip bir ölçüdür (Childers ve diğ., 2002). Aynı zamanda kullanıcıları yeni bir teknoloji kullanmaya yönlendiren önemli bir faktördür (Bruner ve Kumar, 2005; Lee ve diğ., 2005). Bir teknolojik etkinliği zevk alarak ve keyifli bir şekilde kullanan ve teknolojinin sunduğu değer dışında kişisel olarak etkinliği eğlenceli gören kişilerin bu teknolojiyi benimsemeleri ve 
diğerlerinden yaygın olarak kullanması olasıdır (Han ve D. Han, 2001). Teknoloji kullanımı hakkında yapılan çalışmalarda algılanan keyif memnuniyetin bir öncüsü olarak kabul edilmiştir (Hoffman ve diğ., 2003).

\subsection{Memnuniyet}

Tüketici memnuniyeti kavramı, pazarlama literatüründe merkezi bir konuma sahiptir (Churchill ve Surprenant, 1982). Tüketicinin belirli bir ürün veya hizmeti satın alma davranışı sonrasında beklentiler ile gerçek deneyim arasındaki karşılaştırmanın bir sonucu olarak ortaya çıkan duygusal, olumlu ve öznel değerlendirmeyi ifade eden memnuniyet (Oliver, 1981) önceden edinilen deneyim nedeniyle şikayet, sözel ifade, geri satın alma niyeti ve ürün kullanımı gibi temel satın alma sonrası davranışları açıkladığı düşünülmektedir (Oliver ve Westbrook, 1991)

\subsection{Kullanma Niyeti}

Teknoloji kabul modeli, bilgi sistemlerinin benimsenme davranışlarını ve kullanma niyetini açıklamak için araştırmalarda en çok tercih edilen model olmuştur. Teknoloji Kabul Modeli kullanma niyetinin belirlenmesinde, kullanıcının bir sistem hakkındaki inançlarının etkili olduğunu ileri sürmektedir (Davis, 1989). Birçok alanda gerçekleştirilen çalışmalarda Teknoloji Kabul Modeli temel alınarak ve farklı faktörlerle zenginleştirilerek bireylerin yeni bir teknolojiyi kullanma niyetleri açıklanmaya çalışılmıştır (Wu ve Wang, 2005; Agrebi ve Jallais, 2015). Mobil ödeme kullanma niyetine etki eden faktörlerin araştırıldığı çalışmada, algılanan kullanım kolaylığı ve algılanan kullanışıı̆ı̆ın kullanma niyetinin önemli yordayıcıları olduğu belirlenmiştir (Kim ve diğ., 2010). Pai ve Huang'ın çalışmasında bilgi hizmet ve sistem kalitesinin sağlık bilgi sistemi kullanma niyetine etkisinde algılanan kullanışlılığın ve kullanım kolaylığının aracılık ettiği anlaşılmıştır (2011).

\section{VERI VE YÖNTEM}

Veri toplama metodu olarak anket yöntemi seçilmiştir. Anket çalışması kolayda örnekleme yöntemi kullanılarak yapılmıştır. Araştırmanın ana kütlesini Erzurum il sınırlarında yaşayan 18 yaş ve üzeri katılımcılar oluşturmaktadır. Araştırmanın örnek büyüklüğü $n=\frac{\pi(1-\pi)}{(e \div Z)^{2}}$ formülü ile \%5 hata payı ve \%95 güven aralığında alt sınır 384 olarak belirlenmiştir (Kurtuluş, 1998). Tüketicilerin mobil alışveriş uygulamalarını kullanma niyetini etkileyen faktörleri ve bu faktörlerin memnuniyet üzerindeki etkisini incelemek amacıyla 412 kişiye uygulanan anketin hatalı ve eksik cevapları elendikten sonra 389 adet anket formu değerlendirmeye tabi tutulmuştur. Bu çalışmada literatür taraması yapıldıktan sonra amaca en uygun olduğu düşünülen ölçekler şu şekildedir. Algılanan risk beş ifade (Featherman ve Pavlou, 2003; Kang ve diğ., 2012), algılanan kullanışlılık beş ifade (Davis, 1989), algılanan kullanım kolaylığı beş ifade (Davis, 1989; Moore ve Benbast, 1991), algılanan keyif üç ifade (Davis ve diğ., 1992), memnuniyet dört ifade (Bhattacherjee, 2001) ve kullanma niyeti dört ifade (Kim ve diğ., 2010) ile ölçülmüştür. Bu araştırmada uygulanan ölçeklerin cevaplandırılmasında 5'li Likert Tipi kullanılmıştır. Ölçekteki değerlendirme seçenekleri: 1- Kesinlikle Katılmıyorum, 2- Katılmıyorum, 3- Kararsızım, 4- Katılıyorum ve 5- Kesinlikle Katılıyorum şeklindedir.

\section{Araştırmanın hipotezleri:}

- $\quad \mathbf{H}_{1}$ : Tüketicilerin mobil alışveriş uygulamalarına yönelik algıladıkları riskin, memnuniyet üzerinde negatif yönde anlamlı bir etkisi vardır.

- $\quad \mathbf{H}_{2}$ : Tüketicilerin mobil alışveriş uygulamalarına yönelik algıladıkları riskin, kullanma niyeti üzerinde negatif yönde anlamlı bir etkisi vardır.

- $\quad \mathbf{H}_{3}$ : Tüketicilerin mobil alışveriş uygulamalarına yönelik algıladıkları kullanışlılığın, memnuniyet üzerinde olumlu yönde anlamlı bir etkisi vardır.

- $\quad \mathbf{H}_{4}$ : Tüketicilerin mobil alışveriş uygulamalarına yönelik algıladıkları kullanışılığın, kullanma niyeti üzerinde olumlu yönde anlamlı bir etkisi vardır.

- $\quad \mathbf{H}_{5}$ : Tüketicilerin mobil alışveriş uygulamalarına yönelik algıladıkları kullanma kolaylılığının, memnuniyet üzerinde olumlu yönde anlamlı bir etkisi vardır.

- $\quad \mathbf{H}_{6}$ : Tüketicilerin mobil alışveriş uygulamalarına yönelik algıladıkları kullanma kolaylılığının, kullanma niyeti üzerinde olumlu yönde anlamlı bir etkisi vardır.

- $\quad \mathbf{H}_{7}$ : Tüketicilerin mobil alışveriş uygulamalarına yönelik algıladıkları keyifin, memnuniyet üzerinde olumlu yönde anlamlı bir etkisi vardır.

- $\quad H_{8}$ : Tüketicilerin mobil alışveriş uygulamalarına yönelik algıladıkları keyifin, kullanma niyeti üzerinde olumlu yönde anlamlı bir etkisi vardır.

\section{BULGULAR}

Çalışmamıza katılan ve uygun bulunan 389 katılımcıdan alınan cevaplar üzerinden analizler yürütülmüştür. Araştırmada kullanılan analiz yöntemleri; tanımlayıcı istatistikler ve regresyon analizlerinden oluşmaktadır. Verilerin analizinde SPSS 22 istatistik programı kullanılmıştır. Yapılan analizler aşağıda sırasıyla açıklanmıştır.

Araştırmaya katılan bireylerin cinsiyetleri açısından incelendiğinde, 389 kişilik örnek büyüklüğünün, 200 kişinin (\%51,4) 'ünü kadın, 189 kişinin ise $(\% 48,6)$ 'sının ise erkek olduğu görülmektedir. Cevaplayıcıların yaşlarına bakıldığında çok büyük bir bölümünün (\%52,4) 17-24 yaş grubunda olduğu ve bunu \%29,0 ile 25-34 yaş grubunun izlediği görülmektedir. Cevaplayıcıların eğitim seviyesine bakıldığında çalışmaya konu olan bireylerin büyük bölümünün üniversite $(\% 67,4)$ ve bunu $\% 17,2$ ile lise, $\% 9,5$ ile lisansüstü seviyesinde olduğu görülmektedir. Bireylerin gelir düzeyleri incelendiğinde ilk sırayı aylık 1000TL veya daha düşük gelir elde eden grubun aldığı (\%39,8), ikinci sırada ise $\% 19,8$ 
ile aylık 2001-3000 TL arasında gelir elde edenlerin geldiği görülmektedir. Meslekler itibarıyla öğrenci ve memurların diğer meslek gruplarına göre daha çok sayıda oldukları görülmektedir.

Değişkenlerin genel ortlamalarına bakıldığında, algılanan riskin genel ortalaması $(3,81)$ yüksek düzeydedir. Cevaplayıcıların algılanan kullanışlılığa ilişkin değerlendirmeleri $(3,62)$ 'dir. Bunu algılanan keyif $(3,41)$ takip etmektedir. Cevaplayıcıların nispeten en düşük değerlendirdikleri boyut algılanan risk $(3,02)^{\prime}$ dir. Bu sonuç mobil alışveriş uygulamalarının algılanan risk açısından düşük algılandığı şeklinde yorumlanabilir. Cevaplayıcıların mobil alışveriş uygulamalarına yönelik memnuniyet hakkındaki genel değerlendirmeleri $(3,48)$, kullanma niyeti hakkındaki genel değerlendirmeleri $(3,75)^{\prime}$ dir.

Tüketicilerin mobil alışveriş uygulamalarına yönelik algıladıkları risk, kullanışlılık, kullanım kolaylığı ve keyifin memnuniyete etkisinin incelenmesi amacıyla regresyon analizi yapılmıştır. Oluşturulan regresyon modeli 0,05 önem düzeyinde istatistiki açıdan anlamlıdır ve $R^{2}$ değeri 0,350 olarak bulunmuştur. Buna göre memnuniyeti, modeldeki bağımsız değişkenler olan algılanan risk, algılanan kullanışlılık, algılanan kullanım kolaylığı ve algılanan keyifi ancak \%35 oranında açıklayabilmektedir. Modelde yer alan algılanan risk, algılanan kullanışlılık, algılanan kullanım kolaylığı ve algılanan keyif değişkenleri memnuniyeti etkilemektedir. $(\beta=-0,159$ : $P<0.000 ; \beta=0,209$ : $P<0,000$; $\beta=0,348: P<0,000 ; \beta=0,119$ : $P<0,009)$ Bu sonuçlar bağlamında mobil alışveriş uygulamalarına yönelik algılanan risk, memnuniyet üzerinde etkisini öngören $\mathrm{H} 1$ hipotezi kabul, algılanan kullanışlılı̆ın memnuniyet üzerinde etkisini öngören H3 hipotezi kabul, algılanan kullanım kolaylılığının memnuniyet üzerinde etkisini öngören $\mathrm{H} 5$ hipotezi kabul ve algılanan keyifin memnuniyet üzerinde etkisini öngören $\mathrm{H} 7$ hipotezi kabul edilmiştir.

Tüketicilerin mobil alışveriş uygulamalarına yönelik algıladıkları risk, kullanışlılık, kullanım kolaylığı ve keyifin kullanma niyeti üzerindeki etkisinin incelenmesi amacıyla regresyon analizi yapılmıştır. Oluşturulan regresyon modeli 0.05 önem düzeyinde istatistiki açıdan anlamlıdır ve $\mathrm{R}^{2}$ değeri 0.480 olarak bulunmuştur. Buna göre kullanma niyetini, modeldeki bağımsız değişkenler olan algılanan risk, algılanan kullanışlılık, algılanan kullanım kolaylığı ve algılanan keyifi ancak \%48 oranında açıklayabilmektedir. Modelde yer alan algılanan kullanışlılık, algılanan kullanım kolaylığı ve algılanan keyif değişkenleri kullanma niyetini etkilemekte $(\beta=0,165: P<0.000 ; \beta=0,477: P<0,000 ; \beta=0,215$ : $P<0,000)$ algılanan risk ise kullanma niyetini etkilememektedir. $(\beta=0,008$ : $P>0,841)$ Bu sonuçlar bağlamında mobil alışveriş uygulamalarına yönelik algılanan kullanışlılığın kullanma niyeti üzerinde etkisini öngören H4 hipotezi kabul, algılanan kullanım kolaylılı̆ının kullanma niyeti üzerinde etkisini öngören $\mathrm{H} 6$ hipotezi kabul, algılanan keyifin kullanma niyeti üzerinde etkisini öngören $\mathrm{H} 8$ hipotezi kabul ve algılanan riskin kullanma niyeti üzerinde etkisini öngören $\mathrm{H} 2$ hipotezi red edilmiştir.

\section{SONUÇ}

Araştırma için belirlenen 8 hipotezden 7'si kabul 1'i red edilmiştir. Kavramsal modelin bağımsız değişkenleri olan algılanan kullanışılık, algılanan kullanım kolaylığı ve algılanan keyifin memnuniyet ve kullanma niyeti üzerindeki etkisi incelendiğinde hem memnuniyet hem de kullanma niyeti üzerinde etkili olduğu görülmektedir. Ancak katılımcıların algılanan risk seviyelerinin kullanma niyetine etkisinin olmadığı ortaya çıkmıştır. Bu çalışmada, daha önceki araştırmalarla tutarlı olarak, algılanan kullanışlılık, algılanan kullanım kolaylığı ve algılanan keyifin memnuniyet ve kullanma niyeti üzerinde büyük rol oynadığı gözlemlenmiştir (Thakur ve Srivastava, 2013; Wu ve Wang, 2005). Mobil alışveriş uygulamaları ile kullanıcının etkileşimini geliştirmek ve kullanma niyetini artırmak için algılanan yararlılık, kullanım kolaylığı ve keyif üzerinde odaklanılmalıdır. Son derece etkili, yararlı özellikler ve işlevler ekleyerek kullanıcı dostu uygulamalar geliştirilerek kullanıcıların genel alışveriş deneyimlerini iyileştirmek ve kullanma niyetini artırmak mümkündür.

\section{KAYNAKLAR}

Bhattacherjee, A. (2001). An empirical analysis of the antecedents of electronic commerce service continuance. Decision support systems, 32(2), 201-214.

Bruner II, G. C., Kumar, A. (2005). Explaining consumer acceptance of handheld Internet devices. Journal of business research, 58(5), 553558.

Childers, T. L., Carr, C. L., Peck, J., Carson, S. (2002). Hedonic and utilitarian motivations for online retail shopping behavior. Journal of retailing, 77(4), 511-535.

Churchill Jr, G. A., Surprenant, C. (1982). An investigation into the determinants of customer satisfaction. Journal of marketing research, 491-504.

Dai, H., Palvi, P. C. (2009). Mobile commerce adoption in China and the United States: a cross-cultural study. ACM SIGMIS Database: the DATABASE for Advances in Information Systems, 40(4), 43-61.

Davis, F. D. (1989). Perceived usefulness, perceived ease of use, and user acceptance of information technology. MIS quarterly, 319-340.

Davis, F. D., Bagozzi, R. P., Warshaw, P. R. (1989). User acceptance of computer technology: a comparison of two theoretical models. Management science, 35(8), 982-1003.

Davis, F. D., Bagozzi, R. P., Warshaw, P. R. (1992). Extrinsic and intrinsic motivation to use computers in the workplace. Journal of applied social psychology, 22(14), 1111-1132.

Dowling, G. R., Staelin, R. (1994). A model of perceived risk and intended risk-handling activity. Journal of consumer research, 21(1), 119134.

Featherman, M. S., Pavlou, P. A. (2003). Predicting e-services adoption: a perceived risk facets perspective. International journal of humancomputer studies, 59(4), 451-474. 
Fishbein, M., Ajzen, I. (1975). Belief, attitude, intention and behavior: an introduction to theory and research.

Gefen, D., Straub, D. W. (2003). Managing user trust in B2C e-services. E-service Journal, 2(2), 7-24.

Gillett, P. L. (1976). In-home shoppers. An overview. The Journal of Marketing, 81-88.

Giovannini C. J., Ferreira J. B., Silva J. F., Ferreira D. B. (2015). The effects of trust transference, mobile attributes and enjoyment on mobile trust. BAR, Rio de Janeiro, 12 (1/5), 88-108.

Han, J., Han, D. (2001). A framework for analyzing customer value of internet business. JITTA: Journal of Information Technology Theory and Application, 3(5), 25.

Kang, H., Lee, M. J., Lee, J. K. (2012). Are you still with us? A study of the post-adoption determinants of sustained use of mobile-banking services. Journal of Organizational Computing and Electronic Commerce, 22(2), 132-159.

Khalifa, M., Ning Shen, K. (2008). Explaining the adoption of transactional B2C mobile commerce. Journal of enterprise information management, 21(2), 110-124.

Kim, C., Mirusmonov, M., Lee, I. (2010). An empirical examination of factors influencing the intention to use mobile payment. Computers in Human Behavior, 26(3), 310-322.

Kim, D. J., Ferrin, D. L., Rao, H. R. (2008). A trust-based consumer decision-making model in electronic commerce: the role of trust, perceived risk, and their antecedents. Decision support systems, 44(2), 544-564.

Kim, H. W., Chan, H. C., Gupta, S. (2007). Value-based adoption of mobile internet: an empirical investigation. Decision support systems, 43(1), 111-126

King, W. R., He, J. (2006). A meta-analysis of the technology acceptance model. Information \& management, 43(6), 740-755.

Kucukusta, D., Law, R., Besbes, A., Legohérel, P. (2015). Re-examining perceived usefulness and ease of use in online booking: the case of Hong Kong online users. International Journal of Contemporary Hospitality Management, 27(2), 185-198.

Kurtuluş, K. (1998). Pazarlama Araştırmaları. iü İşletme Fakültesi Yayınları No 274, 6. Baskı İstanbul.

Lee, M. K., Cheung, C. M., Chen, Z. (2005). Acceptance of Internet-based learning medium: the role of extrinsic and intrinsic motivation. Information \& management, 42(8), 1095-1104.

Lee, Y., Kozar, K. A., Larsen, K. R. (2003). The technology acceptance model: past, present, and future. Communications of the Association for information systems, 12(1), 50 .

Mitchell, V. W. (1992). Understanding consumers' behaviour: can perceived risk theory help?. Management Decision, 30(3).

Moore, G. C., Benbasat, I. (1991). Development of an instrument to measure the perceptions of adopting an information technology innovation. Information systems research, 2(3), 192-222.

Novak, T. P., Hoffman, D. L., Duhachek, A. (2003). The influence of goal-directed and experiential activities on online flow experiences. Journal of consumer psychology, 13(1-2), 3-16.

Oliver, R. L. (1981). Measurement and evaluation of satisfaction processes in retail settings. Journal of retailing.

Pai, F. Y., Huang, K. I. (2011). Applying the technology acceptance model to the introduction of healthcare information systems. Technological Forecasting and Social Change, 78(4), 650-660.

Ross, I. (1975). Perceived risk and consumer behavior: a critical review. ACR North American Advances.

Shih, H. P. (2004). An empirical study on predicting user acceptance of e-shopping on the Web. Information \& Management, 41(3), 351368.

Thakur, R., Srivastava, M. (2013). Customer usage intention of mobile commerce in India: an empirical study. Journal of Indian Business Research, 5(1), 52-72.

Tsu Wei, T., Marthandan, G., Yee-Loong Chong, A., Ooi, K. B., Arumugam, S. (2009). What drives Malaysian m-commerce adoption? An empirical analysis. Industrial Management \& Data Systems, 109(3), 370-388.

Venkatesh, V., Davis, F. D. (2000). A theoretical extension of the technology acceptance model: four longitudinal field studies. Management science, 46(2), 186-204.

Venkatesh, V., Morris, M. G., Davis, G. B., Davis, F. D. (2003). User acceptance of information technology: toward a unified view. MIS quarterly, 425-478.

Westbrook, R. A., Oliver, R. L. (1991). The dimensionality of consumption emotion patterns and consumer satisfaction. Journal of consumer research, 18(1), 84-91.

Wu, J. H., Wang, S. C. (2005). What drives mobile commerce? An empirical evaluation of the revised technology acceptance model. Information \& management, 42(5), 719-729. 